\title{
PROPRIEDADES RURAIS PEDAGÓGICAS ENQUANTO ESPAÇOS EDUCATIVOS NA PROMOÇÃO DA EDUCAÇÃO AMBIENTAL
}

\author{
Angela Luciane Klein ${ }^{1}$ \\ Ivo Elesbão \\ Marcelino de Souza ${ }^{3}$
}

Resumo: $O$ estudo teve como objetivo analisar as propriedades rurais pedagógicas enquanto locais para a promoção da Educação Ambiental. Para tal, utilizou-se a pesquisa bibliográfica e entrevistas semiestruturadas, realizadas com os donos das propriedades localizadas nos Estados de Santa Catarina, Distrito Federal e São Paulo. Os resultados obtidos apontam para a possibilidade de desenvolvimento de atividades educativas nas propriedades rurais que podem promover aprendizados relacionados às questões ambientais, aos cuidados com os animais, as plantas e a terra. Conclui-se que estas propriedades rurais possuem potenciais para a promoção da Educação Ambiental baseadas na aprendizagem pela experiência, permitindo aos sujeitos uma conexão com o ambiente.

Palavras-chave: Propriedades Rurais Pedagógicas; Educação Ambiental; Experiências Práticas.

1Doutoranda do Programa de Pós-Graduação em Educação da Universidade Federal do Paraná (UFPR). Email: angelaklain@yahoo.com.br

2 Professor Associado do Departamento de Turismo, Centro de Ciências Sociais e Humanas da Universidade Federal de Santa Maria (UFSM). E-mail: ivoelesbao@yahoo.com.br

3 Professor Associado da Faculdade de Ciências Econômicas e dos Programas de Pós-Graduação em Agronegócios e Desenvolvimento Rural da Universidade Federal do Rio Grande do Sul (UFRGS). E-mail: marcelino.souza@uol.com.br 


\section{Introdução}

As preocupações acerca do meio ambiente e do futuro do nosso planeta tem tornado a temática da Educação Ambiental (EA) cada vez mais importante e necessária. Há, pois, uma urgência no desenvolvimento de ações mais eficazes, de intervenções coletivas mais concretas envolvendo toda a sociedade, capazes de favorecer a reflexão acerca da inter-relação e interdependência entre homem e natureza, dentro de uma perspectiva relacional, que favoreça a religação dos saberes, ou seja, substituindo o pensamento dicotômico, que separa, por um pensamento que une, conforme destaca Morin (2003).

Nesse processo, a escola assume uma função essencial, no sentido de contribuir para a formação de sujeitos mais críticos e responsáveis socioambientalmente. Mas como conseguir atingir tal objetivo diante de uma conjuntura educacional baseada em uma estrutura curricular conteudista? Como tornar o processo de ensino e aprendizagem mais envolvente e atrativo aos olhos dos estudantes? Como promover a formação socioambiental cidadã das crianças e adolescentes num cenário marcado pela degradação socioambiental?

A complexidade que envolve tal problemática tem gerado muitas discussões e reflexões, dando abertura para a criação e expansão de novos espaços socioeducativos, cuja finalidade é contribuir para o aprendizado das crianças e adolescentes, porém, sem o mesmo grau de sistematização presente nas escolas. Estes espaços educativos não formais ${ }^{4}$ têm ganhado notoriedade nas últimas décadas, na medida em que possibilitam às crianças e adolescentes um contato mais direto com os elementos da natureza, favorecendo experiências diferenciadas.

É nesse contexto que emergem as Propriedades Rurais Pedagógicas que até pouco tempo eram consideradas como locais destinados unicamente à moradia das famílias rurais e à produção agrícola e pecuária, mas que passaram a receber um novo enfoque a partir do momento em que seus proprietários abriram as portas para receber grupos de estudantes, com o propósito de mostrar seu trabalho, evidenciando os saberes e fazeres do homem do campo e sua relação com a terra e o meio ambiente. Esse conjunto de atividades desenvolvidas em propriedades rurais recebe 0 nome de turismo rural pedagógico ${ }^{5}$, uma prática ainda recente no cenário brasileiro, mas bem-sucedida no cenário internacional.

Em países como França (CAFFARELLI et. al., 2010), Noruega (JOLLY et. al. 2004) e Itália (NAPOLI, 2006; NASOLINI, 2005), as Propriedades Rurais Pedagógicas têm se revelado como espaços de caráter exemplar dentro de uma

\footnotetext{
${ }^{4}$ Entende-se por educação não formal aquelas atividades com caráter de intencionalidade, porém com baixo grau de estruturação e sistematização, implicando certamente relações pedagógicas, mas não formalizadas (LIBÂNEO, 2004, p. 69).

5 Conjunto de atividades práticas realizadas no âmbito da propriedade rural, voltadas para grupos de escolares e que utiliza como recurso didático as atividades agrícolas, a produção agropecuária e os recursos naturais e culturais ali existentes (KLEIN, 2013).
}

Revbea, São Paulo, V. 13, № 3: 194-208, 2018. 
perspectiva de desenvolvimento sustentável, promovendo a Educação Ambiental, nutricional e cultural de maneira integrada e eficaz.

Partindo desses pressupostos, o presente artigo busca analisar as Propriedades Rurais Pedagógicas enquanto espaços educativos estratégicos para a promoção da EA. O estudo foi feito a partir de um recorte do projeto de pesquisa intitulado "O turismo rural pedagógico sob o viés da multifuncionalidade da agricultura: análise a partir de três experiências desenvolvidas nos Estados de Santa Catarina, Distrito Federal e São Paulo"6. Nesse projeto, foram analisadas três experiências diferenciadas que estão sendo desenvolvidas nos Estados de Santa Catarina (Projeto Viva Ciranda), Distrito Federal (Projeto Turismo Rural e Escola - Fazendo Eco) e São Paulo (Roteiro do Turismo Rural Pedagógico do Estado de São Paulo).

\section{Educação Ambiental e suas contribuições no cenário atual: breves reflexões}

A questão ambiental tem recebido grande destaque nos tempos atuais. São conferências mundiais, acordos internacionais, leis, decretos, um conjunto de ações que tem se expandido e ganhado cada vez mais força, especialmente nas últimas décadas, cujas problemáticas ambientais tornaram-se mais agravantes. Em meio a este contexto, países como o Brasil passaram a implementar uma série de políticas públicas visando legitimar e fomentar iniciativas em prol do meio ambiente, tendo a Educação Ambiental como principal instrumento de transformação do indivíduo e da sociedade.

Dentre os principais documentos criados ao longo dos últimos 20 anos, destacamos a Lei $n^{\circ}$ 9.795/99, que estabeleceu a Política Nacional de Educação Ambiental (BRASIL, 1999), o Decreto № 4.281/2002, que regulamenta a Lei que institui a Política Nacional de Educação Ambiental (BRASIL, 2002) e o Programa Nacional de Educação Ambiental (PRONEA), que instituiu ações nos âmbitos da EA formal e não formal (BRASIL, 2005).

Tais iniciativas governamentais tiveram um papel muito importante no processo de implementação da EA no cenário brasileiro. Contudo, não podemos nos esquecer de que o avanço da EA depende mais de uma mudança na percepção de vida e da espécie humana do que da criação e constituição de leis e planos estratégicos que, na maioria das vezes, permanece apenas no papel. Como bem expõe Morin (2000, p. 14), "o que agrava a dificuldade de conhecer nosso Mundo é o modo de pensar que atrofiou em nós, em vez de desenvolver a aptidão de contextualizar e de globalizar".

Assim, o principal desafio da EA vincula-se a esse processo de transformação dos sujeitos, fazendo com que percebam as inter-relações e as

6 Projeto desenvolvido entre os anos de 2012 e 2013 com o apoio financeiro do CNPq (Conselho Nacional de Desenvolvimento Científico e Tecnológico). 
conexões existentes entre a vida do homem e seu ambiente, deixando de lado o pensamento de superioridade centrado em uma visão antropocêntrica cartesiana de mundo, ainda muito presente na sociedade em que vivemos. A quebra desse paradigma seria, portanto, o passo inicial, conforme destaca Guimarães (2007, p. 86):

A natureza é explorada por nossa sociedade como se fosse um recurso inesgotável, vista de forma fragmentada, sem a preocupação e o respeito com as relações dinâmicas do equilíbrio ecológico e sua capacidade de suportar os impactos sobre ela, o que resulta nos graves problemas ambientais da atualidade. A natureza percebida a partir de uma visão mais complexa, em sua totalidade, potencializaria a construção de uma relação entre os seres humanos em sociedade e a natureza de forma mais integrada, cooperativa e, portanto, sustentável socioambientalmente.

Ressalva-se, contudo, que tal tarefa não é simples nem fácil, ao contrário, é complexa, desafiadora e requer muito empenho e força de vontade. Um desafio relacionado à mudança, à criatividade e ao desenvolvimento de propostas educativas que possam envolver e instigar os estudantes a pensar, criar e, sobretudo, agir e transformar seu ambiente. Para Barcelos (2012, p. 21), a construção de um mundo social e ecologicamente mais justo e responsável está intimamente relacionado à constituição de novas metodologias que nos ajudem a "edificar espaços de convivência a partir da solidariedade, de cooperação, da tolerância e do amor, não só com os demais seres humanos, mas, sim, com todas as demais formas de vida existentes no Planeta Terra".

Nesse contexto, a EA emerge como uma prática sócio pedagógica reflexiva e crítica, que "[...] tem o mundo, a realidade-ambiente, como mediador do processo educativo [...]" (DICKMANN, 2015, p. 77); uma prática integrada às realidades socioambientais dos sujeitos "[...] que compreende a sociedade numa perspectiva complexa, em que cada uma de suas partes (indivíduos) influencia o todo (sociedade), mas ao mesmo tempo a sociedade os padrões sociais influenciam os indivíduos" (GUIMARÃES, 2007, p. 89). Uma EA responsável e comprometida com a formação humana e cidadã, que oriente e possibilite aos sujeitos a:

[...] desenvolverem e redimensionarem valores, atitudes, hábitos e costumes cotidianos, em perspectiva de reconstrução das relações entre os seres humanos e, destes, com a natureza - de forma responsável, cidadã e sustentável, em busca de um maior equilíbrio local e global, atual e futuro (DICKMAN, 2015, p. 19). 
Diante dessa perspectiva, destacamos a importância e necessidade de ir além dos muros escolares, utilizando os múltiplos espaços socioeducativos existentes fora das escolas, tornando a educação formal uma das frentes da EA, contudo, não a única. Vale enfatizar a importância do desenvolvimento de ações pedagógicas múltiplas, cujo foco é envolver o estudante, promovendo experiências diferenciadas em contato com a terra, as plantas, os animais e a água, no sentido de instigar reflexões que possibilitem a estes sujeitos a tomada de consciência e a compreensão de que homem e natureza fazem parte do mesmo sistema, numa relação de interdependência. A partir de uma EA sob esta perspectiva é que poderemos iniciar o processo de transformação dos sujeitos e da sociedade.

\section{Práticas educativas e aprendizagem pela experiência}

Conforme ressaltado na seção anterior, a promoção da EA, para ser efetiva, deve estar voltada para a formação socioambiental cidadã dos sujeitos, articulada com a realidade local-global, com vistas a promover a religação dos saberes e a tomada de consciência - individual e coletiva - política, ecológica e ética, de respeito ao Outro, à diversidade cultural e a todas as formas de vida.

A escolha por uma EA com tais características tem como elemento orientador a reflexão, dentro de uma perspectiva crítica, e ainda, a aprendizagem pela experiência. Segundo Yus (2002), a aprendizagem pela experiência compreende um processo que vincula a educação, o trabalho e o desenvolvimento pessoal; um processo que exige métodos ativos, rompendo assim com o esquema tradicional de alunos passivos e receptivos. Trata-se de uma estratégia educativa que teve especial relevância no denominado movimento da educação progressista, que surgiu na América do Norte no final do século XIX em contraposição à natureza autoritária e antidemocrática evidenciada pela escolarização tradicional. Dentre os precursores desse movimento está Jonh Dewey (1859-1952), que critica o saber livresco para ressaltar a experiência, isto é, os métodos ativos.

Para Dewey (1954), a experiência possui um papel central na aprendizagem do sujeito, sendo definida como um processo de renovação da existência física que alarga os conhecimentos, enriquecendo o nosso espírito e dando um significado mais profundo à vida. A educação, por conseguinte, é definida como um processo presente, que acontece a cada dia e não a preparação para o futuro. Consequentemente, a escola não pode ser entendida como um ambiente de preparação para a vida, mas a própria vida, uma instituição que teria como princípio orientador a reconstrução constante da experiência. Vida, experiência e aprendizagem, portanto, são processos que não se podem separar, pois ao mesmo tempo em que vivemos, experimentamos e aprendemos.

A premissa de que toda aprendizagem deveria ser integrada à vida, ou 
mesmo lugar e função que tem na vida, constituiu-se em um dos pontos chaves da proposta metodológica de Dewey. Desse modo, para que não existissem tantas diferenças entre os conteúdos ensinados na escola e as vivências da criança no seu dia a dia, ele propôs uma nova forma de organização curricular vinculada às múltiplas experiências ocorridas na vida das mesmas. Tal proposta dava grande ênfase aos brinquedos, jogos e às atividades práticas que permitissem a observação, a experimentação, despertando nas crianças uma curiosidade intelectual e estimulando suas emoções. Sua preocupação principal voltava-se para uma aprendizagem que se relacionasse com o próprio desenvolvimento intelectual da criança na sua fase de criança (CASTELLER, 2008).

$\mathrm{Na}$ análise de Teixeira (1954), um dos principais méritos presentes na teoria de educação proposta por Dewey foi justamente o de restaurar o equilíbrio existente entre a educação tácita e não formal recebida diretamente na vida e a educação direta expressa nas escolas, integrando dessa forma, a aprendizagem adquirida por meio de um exercício específico (escola) com a aprendizagem adquirida nas experiências sociais (vida).

A valorização da experiência enquanto elemento mediador da aprendizagem traz à tona a ideia do 'aprender fazendo' e do 'aprender sentindo', das múltiplas vivências fora da sala de aula e das relações estabelecidas com os conteúdos escolares, aspectos estes que vão totalmente ao encontro de uma proposta de Educação Ambiental promovida no âmbito das propriedades rurais pedagógicas.

\section{Propriedades Rurais Pedagógicas: conceitos e características}

Compreendidas até então, como locais destinados à moradia das famílias rurais e à produção agrícola e pecuária, as propriedades rurais passaram a receber um novo enfoque a partir do momento em que abriram suas portas para receber grupos de estudantes, mostrando seu trabalho e sua rotina no meio rural, evidenciando seus saberes e fazeres. Trata-se, pois, da prática do turismo rural pedagógico, caracterizado por um conjunto de atividades educativas que utiliza como recurso didático as atividades agrícolas, a produção agropecuária e os recursos naturais e culturais ali existentes.

Nesses termos, de acordo com Bertacci (2005), as propriedades rurais que desenvolvem atividades educativas representam locais que favorecem uma conexão direta entre a cidade e o campo, entre o produtor e o cidadão, entre o agricultor e o consumidor. Por conseguinte, estas estruturas adquirem uma nova dimensão, um novo olhar, tornando-se um lugar de observação e exploração concreta, favorecendo a experiência pessoal.

Pendezza (2014) destaca também que as propriedades rurais pedagógicas se constituem numa importante ferramenta para o desenvolvimento local, além de um excelente instrumento educativo, na medida em que criam 
oportunidades de reflexão objetivando uma abordagem mais completa e consciente sobre a natureza e o meio rural.

Ainda, segundo Nasolini (2005), as atividades educativas que são desenvolvidas nessas propriedades são orientadas por três ideias basilares. A primeira relacionada a uma pedagogia ativa, representada por um conjunto diversificado de atividades práticas e experiências diretas; a segunda associada ao contato direto com animais e plantas em seu ambiente natural; e a terceira referente à oportunidade de encontro e interação entre agricultores e jovens, possibilitando o enriquecimento das experiências destes, por meio da emoção e do conhecimento despertado.

Tais elementos foram corroborados a partir de uma pesquisa científica realizada por Klein (2013) em propriedades rurais pedagógicas no sul do Brasil. De acordo com a autora, as atividades educativas desenvolvidas nestes espaços evidenciam quatro questões-chaves: a primeira relacionada a ideia do 'aprenderfazendo', a segunda referente à Educação Ambiental, a terceira questão associada à valorização da cultura rural e a quarta, diz respeito à educação alimentar e nutricional.

Desse modo, segundo Caffarelli et. al. (2010), as propriedades rurais representam ferramentas pedagógicas eficazes que favorecem o crescimento da consciência do papel social da agricultura e das áreas rurais e, dentro de uma perspectiva de desenvolvimento integrado, contribuem para a valorização dos recursos históricos, arqueológicos e culturais do território, representando, além disso, um meio eficaz de Educação Ambiental e nutricional a ser utilizado para fins educacionais. Também, para Martellini e Ciabotti (2014), as propriedades rurais pedagógicas abrem espaço para experiências que possibilitam uma relação direta com o meio ambiente, despertando nas crianças a curiosidade e enriquecimento interior, aprimorando as habilidades de observação e investigação.

Diante dessa conjuntura, D'Agostinho (2008), expõe que um dos objetivos das atividades desenvolvidas na propriedade rural é, pois, proporcionar formas de viver em harmonia com o meio ambiente, crianças e jovens, por meio de situações concretas e não somente um conhecimento do mundo virtual ao seu redor através da internet e da televisão. A partir dessas experiências, as crianças têm a oportunidade de vivenciar e perceber um mundo que nem sempre é mostrado em sala de aula, podendo descobrir novas sensações e emoções que acabam despertando um sentimento de pertencimento, de conexão, de inter-relação com o seu ambiente (KLEIN et al., 2011).

Nesse sentido, segundo Jolly et al. (2004), a utilização da propriedade rural como recurso pedagógico no cenário atual constitui-se em importante fonte de renda para o agricultor e também, como uma plataforma pedagógica para o ensino e fonte de identidade para uma população que está cada vez mais distante dos espaços naturais. 
As Propriedades Rurais Pedagógicas, desse modo, se destacam no cenário atual como espaços socioeducativos privilegiados, sobretudo, para os estudantes, uma vez que possibilitam aos mesmos a aquisição de diferentes conhecimentos e uma série de vivências práticas junto ao meio rural, à natureza, favorecendo uma experiência dos sentidos, além de possibilitar olhares mais sensíveis e conscientes diante dos diferentes ambientes de vida. Pensar a EA a partir dessas experiências em conexão com as Propriedades Rurais Pedagógicas pressupõe a promoção de um novo modo de sentir e pensar a vida e as relações com o mundo e, sob essa lógica, o desenvolvimento de um sentimento de identidade terrena e de compreensão humana.

\section{Procedimentos metodológicos da pesquisa}

O presente artigo compreende um recorte da pesquisa científica intitulada "O turismo rural pedagógico sob o viés da multifuncionalidade da agricultura: análise a partir de três experiências desenvolvidas nos Estados de Santa Catarina, Distrito Federal e São Paulo", e que teve como principal objetivo analisar a função educativa desempenhada pela agricultura a partir da prática do turismo rural pedagógico e a sua relação com as funções social, ambiental, econômica, cultural e de saúde e segurança alimentar.

Os procedimentos metodológicos utilizados no referido estudo compreenderam a pesquisa bibliográfica acerca da literatura existente e entrevistas semiestruturadas, realizadas com os proprietários, donos das propriedades rurais que fazem parte das três experiências pesquisadas.

A primeira dessas experiências contemplou o estudo do projeto de turismo pedagógico 'Viva Ciranda', no município de Joinville, no Estado de Santa Catarina. O projeto compreende um conjunto de propriedades rurais que desenvolvem atividades pedagógicas voltadas especificamente para crianças do ensino fundamental, num processo de cooperação com a Secretaria da Educação do município.

Nesse projeto, a coleta dos dados foi realizada no mês de março de 2013 e contemplou oito proprietários rurais que desenvolvem atividades educativas voltadas para escolares: Propriedade do Senhor Ango Kersten; Propriedade da Família Schroeder; Propriedade Agrícola da Ilha; Sítio Vale das Nascentes; Apiário PFAU; Propriedade da Família Jacobi; Propriedade Rancho Alegre; e Propriedade Recanto das Arrozeiras.

A segunda experiência estudada refere-se ao Projeto "Turismo Rural e Escola - Fazendo Eco", desenvolvido em Brasília, Distrito Federal. A iniciativa foi uma proposta do Sindicato de Turismo Rural e Ecológico do Distrito Federal em parceria com o Sindicato das Escolas Particulares (SINEPE) e com o Serviço Brasileiro de Apoio às Micro e Pequenas Empresas (SEBRAE), tendo como objetivo principal promover a ampliação dos espaços escolares a partir de atividades de caráter pedagógico desenvolvidas em nove propriedades 
participantes. Foram visitados para a coleta de dados da pesquisa cinco empreendimentos, sendo eles os seguintes: Centro de Turismo Rural Pedagógico Ver de Perto, Fazenda Recreio Dinizlândia, Fazenda Velha, Rancho Canabrava e Solar da Águia. As entrevistas foram realizadas entre os dias 26 de fevereiro e 1 de março de 2013.

A terceira experiência que foi objeto da pesquisa diz respeito ao Roteiro do Turismo Rural Pedagógico do Estado de São Paulo. O referido roteiro contempla um conjunto de 16 propriedades rurais presentes em 10 municípios localizados no Estado de São Paulo e um fora do estado, em Minas Gerais e que compreende o Roteiro de Turismo Rural Pedagógico do Estado de São Paulo. As propriedades pesquisadas foram as seguintes: Chácara do Rosário, Fazenda Santo Antônio da Bela Vista e Camping Casarão situadas no município de Itu; Fazenda Nova e Fazenda Santo Antônio da Água Limpa, ambas localizadas no município de Mococa; Fazenda Ituaú localizada no município de Salto; Sítio Sakaguti localizado no município de Piedade; Fazenda dos Coqueiros e Fazenda Loanda, ambas situadas no município de Bananal. Nestes empreendimentos, a coleta de dados ocorreu no período de janeiro a agosto de 2013.

Ressaltamos que os depoimentos dos empreendedores foram transcritos e utilizados na análise dos dados, mas sem identificação, sendo utilizado para isso um código formado por letras e números. As letras "SC" para Santa Catarina, "DF" para o Distrito Federal e "SP" para São Paulo e os números que indicam a ordem da realização das entrevistas.

\section{Análise e discussão dos resultados}

Conforme constatado, as atividades propostas em cada propriedade nas três experiências analisadas são diversas e contemplam uma série de questões associadas à $E A$, e também, à educação nutricional e valorização da cultura rural, de maneira integrada. Desse modo, analisamos mais detalhadamente cada experiência, buscando destacar não apenas as atividades propostas, mas também, os objetivos das mesmas e o ponto de vista dos proprietários sobre os roteiros educativos realizados e sua relação com as questões ambientais.

Nas propriedades do projeto Viva Ciranda, no município de Joinville, em Santa Catarina, praticamente todas as atividades educativas propostas utilizam as atividades produtivas e/ou os bens naturais e culturais existentes em seus roteiros voltados para os grupos escolares. O contato com os animais constitui um dos aspectos mais destacados pelos proprietários. Trata-se de uma atividade que desperta o interesse das crianças, tornando-se uma das principais atrações do roteiro. Segundo os depoimentos dos entrevistados, o roteiro de atividades proposto contempla vários temas: 
A gente trabalha aqui diferentes temas, meio ambiente, resgate histórico, plantações, produção de melado, animais, sistema de tratamento de água por zona de raízes (SC1).

Nosso roteiro é bem voltado para o ambiente. Explicamos sobre os pássaros e árvores nativos, a separação do lixo, o ciclo das águas, mostramos a mata, as nascentes do rio, realizamos brincadeiras para que descubram as espécies de animais que temos na nossa região e também, deixamos tratar peixes e outros animais que temos aqui. $\mathrm{E}$ as crianças sempre gostam muito (SC4).

Observamos assim, um interesse declarado por parte dos proprietários em contribuir para a conscientização das crianças sobre a importância de cuidar o meio ambiente. Assuntos como a qualidade da água e do ar, os cuidados com os animais e as plantas, o processo de produção agroecológica e a preservação dos recursos hídricos estão entre os mais citados pelos proprietários. São temas abordados durante as atividades, em um contexto que permite aos grupos de estudantes relacionarem a teoria (aquilo que aprenderam na sala de aula) com a prática (as experiências vivenciadas na propriedade, incrementadas pelos depoimentos dos proprietários). Além disso, tais aspectos tornam o processo de aprendizagem muito mais agradável e atrativo aos olhos das crianças e adolescentes. Conforme expõe um dos entrevistados:

Mostrar às crianças a importância das plantas para a vida delas, para o meio ambiente, mostrar a importância de uma árvore. Ensinar elas a cuidar das flores, mostrar o jardim e aí mostrar que isso não acontece sozinho, que precisa de cuidado, que a planta precisa ser plantada, semeada e ter os seus devidos cuidados para que a plantinha cresça e fique bonita (SC3).

A questão ambiental, desse modo, constitui um dos elementos orientadores das atividades educativas desenvolvidas nestas propriedades. Tal afirmativa evidencia-se em cada roteiro analisado, cujas atividades abrangem desde a visitação à horta e contato direto com animais como coelhos, patos, cabras (Sítio da Família Schroeder) e plantações de cana-de-açúcar (Propriedade do Senhor Ango Kersten) até trilhas em meio à mata nativa (Propriedade Agrícola da Ilha), aulas práticas sobre animais silvestres e sobre o ciclo das águas (Sítio Vale das Nascentes), a produção de arroz (Recanto das Arrozeiras) e produção de mel (Apiário PFAU). Este conjunto de aspectos vai ao encontro do que propõem Martellini e Ciabotti (2014), Caffarelli et al. (2010) e Klein et al. (2011), evidenciando assim, as inúmeras potencialidades dessas propriedades em prol de uma EA cujos princípios constitutivos encontram-se 
apoiados numa relação intrínseca e interdependente entre homem e natureza.

A preocupação com o meio ambiente nestas propriedades contempla também a produção de alimentos. A partir de algumas situações, muitas crianças "descobrem" a origem de alguns alimentos, a exemplo do leite e dos ovos, além de conhecerem o processo de produção orgânica:

Muitos vêm aqui e acham que o leite sai da geladeira ou da caixinha, então essa experiência de poder ordenhar uma cabra, que são animais dóceis, mostrando de onde vem o leite, o ovo e também mostrar para elas a parte da produção orgânica, que tem como trabalhar sem agrotóxico e com qualidade, tudo isso é muito importante (SC2).

Nasolini (2005) chama a atenção para este desconhecimento por parte das novas gerações em relação à origem dos alimentos e do trabalho na terra. De acordo com uma pesquisa feita pelo Conselho Europeu dos Jovens Agricultores, com 2.400 crianças com idade entre 9 e 10 anos, cerca de $50 \%$ não sabiam de onde vinha o açúcar, $75 \%$ desconheciam a origem do algodão e somente $40 \%$ conseguiram relacionar o pão de trigo com a farinha. Nesse sentido, as propriedades rurais pedagógicas emergem como ferramentas de aprendizagem, espaços pedagógicos com múltiplas potencialidades e que permitem realizações de atividades pedagógicas com os estudantes em conexão com o meio ambiente.

Esta relação com o meio ambiente também é evidenciada nas atividades educativas desenvolvidas nas experiências do Distrito Federal. De acordo com os proprietários "nós temos várias atividades, porque o nosso trabalho todo é baseado na preservação do meio ambiente" (DF3) e "(...) isso a gente passa muito pra criança, gente isso aqui é a nossa casa, nosso ambiente, nós temos que preservar, isso aí é batido desde que a criança chega até a hora que ela sai. É a ideia de mostrar a importância da preservação da natureza para a criança" (DF5).

Entre os principais aspectos relacionados à EA que podem ser apreendidos a partir das atividades socioeducativas desenvolvidas nas propriedades, estão a preservação do meio ambiente, evidenciado no cuidado com água e a vegetação, além do lixo e sua destinação: "Ali nós temos o laboratório com minhocário, com a parte seletiva de lixo. Ensina a criança a separar o sólido do líquido, do alimento, do metal, do vidro" (DF1); "Aqui a gente fala muito sobre a preservação, a reutilização e os cuidados com a água, isso aqui é muito debatido (DF3); "A gente trabalha muito essa parte da vegetação, do clima, a Educação Ambiental, como que você procede na propriedade rural" (DF4).

Quanto às atividades que mais se destacam entre os estudantes visitantes, os empreendedores apontam aquelas que possuem um caráter mais 
lúdico e também, aquelas relacionadas à produção de alimentos e o cuidado com a terra. De acordo com os entrevistados, o benefício que as atividades educativas podem trazer para os alunos visitantes, envolve a produção de alimentos saudáveis e sem agrotóxicos, "fundamentalmente é a vivência da coisa, é ver de perto, ver de perto uma horta orgânica, uma casa de farinha" (DF2). Também "é que a comida é saudável, não tem nenhum defensivo agrícola" (DF3). Com base nos depoimentos evidencia-se novamente a ideia do "aprender-fazendo" (KLEIN, 2013), assegurando, neste caso, uma compreensão mais aprofundada acerca das questões relacionadas com a alimentação.

Nos empreendimentos pesquisados no Estado de São Paulo, esta proposta também foi averiguada, observando-se uma preocupação voltada, sobretudo, para a "preservação da água, da natureza e o desenvolvimento sustentável (uso dos recursos naturais sem agressão ao meio ambiente)" (SP3). Podem ser aprendidas características dos diferentes biomas, preservação das matas, conscientização do uso da água, a questão do lixo, reciclagem, entre outros. Todos estes elementos contemplam os conteúdos estudados em sala de aula, mas com diferença na forma - menos sistemáticos e teóricos e mais articulados com a vida - como são mostrados e discutidos com os alunos, e em consonância com a abordagem proposta por vários autores que estudam a temática das propriedades rurais pedagógicas (JOLLY et al. 2004).

A produção de alimentos é outro aspecto destacado nas atividades dessas propriedades. Alguns exemplos passam pelo passeio no cafezal e nas diversas etapas além da plantação, explicando qual é o melhor tipo, como se separam os grãos, como a produção é livre de agrotóxicos. Em outro empreendimento é abordado o ciclo de produção do caqui, produzido de forma natural, sem agrotóxicos e produtos químicos. Em outro são abordadas noções da alimentação utilizada na época (século XIX e XX, como por exemplo, o consumo da própria produção agropecuária e a utilização da água para consumo).

A partir das análises realizadas, verificou-se um conjunto de elementos que convergem visivelmente com as bases conceituais da EA, dentro de uma perspectiva com ênfase na formação socioambiental cidadã e desenvolvida a partir de experiências práticas, do aprender-fazendo, do vivenciar (BERTACCl, 2005; NASOLINI, 2005). Nesse sentido, as Propriedades Rurais Pedagógicas estudadas evidenciam-se como espaços socioeducativos privilegiados que possibilitam aos estudantes uma experiência dos sentidos e de sensibilização para com a natureza, bem como possibilitando a compreensão das interdependências entre seres humanos e natureza. As propriedades rurais, desse modo podem ser compreendidas como verdadeiros laboratórios de aprendizagem ao ar livre e que favorecem a formação de sujeitos mais responsáveis ambientalmente, preocupados com o cuidar, e não apenas com o preservar, percebendo a natureza como um bem precioso e não apenas como um recurso a ser explorado pelo homem. 


\section{Considerações finais}

A análise das informações coletadas nos permitem constatar um conjunto de elementos associados à prática de uma EA que de fato possa promover a religação dos diferentes saberes, a reflexão, a conscientização e a sensibilização, contribuindo assim, para mudanças nos hábitos e atitudes das crianças e adolescentes. Trata-se do desenvolvimento de um modelo de EA centrado em atividades socioeducativas práticas, desenvolvidas em espaços que vão além do espaço escolar, em meio à natureza, junto à terra, aos animais, às plantas e, favorecendo a partir disso, a compreensão da inter-relação e interdependência envolvendo $o$ homem e natureza e um sentido de pertencimento, de compreensão do valor de cada ambiente de vida.

As Propriedades Rurais Pedagógicas, nesse contexto, destacaram-se como espaços privilegiados, na medida em que possibilitaram aos estudantes um rol de experiências diferenciadas e com uma série de informações que poderiam vir a ser trabalhadas em sala de aula, unindo teoria e prática, evidenciando o desenvolvimento de um currículo mais integrado e voltado para a vida dos sujeitos. Aspectos como o ciclo das águas, cuidado com os animais, o processo de produção dos alimentos, bem como, o respeito ao meio ambiente constituíram-se em questões chave nestes espaços.

Assim, pelas características apresentadas, as Propriedades Rurais Pedagógicas emergem como verdadeiros laboratórios de aprendizagem ao ar livre, favorecendo práticas educativas eficazes, na medida em que possibilitam aos sujeitos envolvidos vivenciar, sentir, experimentar, observar, tocar tudo aquilo que está ao seu redor, ao ambiente rural, numa relação de conexão com o meio ambiente.

A partir da análise das três experiências é possível desvelar uma ferramenta educativa de grande relevância nos dias atuais e que, justamente por sua eficácia, deveria estar acessível a todas as escolas, e, consequentemente, a oportunidade dos estudantes perceberem um mundo que nem sempre é mostrado em sala de aula ou então, na televisão ou na internet. É por meio de propostas contemplando experiências como estas que talvez possamos despertar o interesse dos estudantes, tornando o processo de aprendizagem mais envolvente e atrativo, tendo a EA como fio condutor de toda a formação humana, contribuindo para o desenvolvimento de valores necessários ao bem viver e à sustentabilidade socioambiental.

\section{Agradecimentos}

Ao Conselho Nacional de Desenvolvimento Científico e Tecnológico (CNPq), pelo apoio financeiro à pesquisa através de dois editais: Universal CNPq № 14/2011 e Chamada MCTI/CNPq/MEC/CAPES N 07/2011. 


\section{Referências}

BARCELOS, V. Educação Ambiental: sobre princípios, metodologias e atitudes. 4 ed. Petrópolis: RJ, 2012.

BERTACCI, M. La scuola e le fattorie didattiche. In: BERTOLINI, S. (Ed.). Nuovi educatori ambientali: Esperienze seminariali nel Master in Educazione Ambientale. v. 4, Bologna: Regione Emilia-Romagna, 2005. p. 240-245 . Disponível em: <http://www.ermesambiente.it/wcm/infea/sezioni laterali/formazio ne/master in ea/Master EA/master ea/infean4.pdf>. Acesso em: 20/05/2016.

BRASIL. Lei n. 9795 - 27 de abril de 1999. Dispõe sobre a Educação Ambiental. Política Nacional de Educação Ambiental. Brasília, 1999.

BRASIL. Lei no 4.281, de 25 de junho de 2002. Institui a Política Nacional de Educação Ambiental; altera a Lei ํo 9.975, de 27 de abril de 1999; e dá outras providências. Presidência da República - Casa Civil, Brasília, 2002.

BRASIL. ProNEA - Programa Nacional de Educação Ambiental. Ministério do Meio Ambiente, Diretoria de Educação Ambiental; Ministério da Educação, Coordenação Geral de Educação Ambiental. - 3 ed - Brasília: MMA, DF, 2005.

CAFFARELLI, J.; COQUILLAUD, M.-S.; DANIEL, V.; THOU, M. Creér une ferme pédagogique: de l'idée à la realization. França: Educagri Editions, 2010.

CASTELLER, L. D. A centralidade de 'experiência' na concepção educacional de John Dewey: uma análise de apropriações no pensamento pedagógico brasileiro. 2008. Dissertação (Mestrado em Educação). Universidade do Extremo Sul Catarinense, Criciúma, 2008. 114 p. Acesso em: 17/05/2016. Disponível em http://www.bib.unesc.net/biblioteca/sumario/00003D/00003DFC.pdf

D'AGOSTINO, L. II profilo e le caratteristiche di una Fattoria Didattica. In: La rete delle Aziende e delle Fattorie Didattiche in Sicilia. La documentazione dell'esperienza. Vol. 2. Regione Sicilia/Arpa, 2008. p. 23-28. Disponível em $<$ www.arpa.sicilia.it/UploadDocs/1369 Fattorie Didattiche.pdf $>$ Acesso em julho de 2011.

DEWEY, J. Vida e educação. 5ed. São Paulo: Nacional, 1954.

DICKMANN, I. A formação de educadores ambientais: contribuições de Paulo Freire. 2015. Tese (Doutorado em Educação) - Programa de Pós-Graduação em Educação, Universidade Federal do Paraná, Curitiba. 2015.

GUIMARÃES, M. Educação Ambiental: participação para além dos muros da escola. In: MELLO, S. S.; TRAJBER, R. Vamos cuidar do Brasil: conceitos e práticas em Educação Ambiental na escola. Brasília: Ministério da Educação, Coordenação Geral de Educação Ambiental: Ministério do Meio Ambiente, Departamento de Educação Ambiental: UNESCO, 2007. p. 85-94.

JOLLY, L.; KROGH, E.; NERGAARD, T.; PAROW, K.; VERSTAD, B. The Farm as a Pedagogical Resource: background for and evaluation of the co-operation between agriculture and primary school in the county of Nord-Trondelag, Norway. 
In: SIXTH EUROPEAN IFSA SYMPOSIUM, 2004, Portugal. Proceedings of the Sixth European IFSA Symposium: Farming and Rural Systems - Research and Extension. Vila Real, Portugal: UTAD, 2004. p. 497-507. Disponível em: $<$ www.livinglearning.org/.../The Farm as a Pedagogical ResourcePortugal.pdf >. Acesso em: 05/03/2016.

KLEIN, A.; TROIAN, A.; SOUZA, M. O turismo rural pedagógico e a Educação Ambiental: as ações pedagógicas desenvolvidas na fazenda quinta da estância grande Viamão (RS). Revista Eletrônica do Mestrado em Educação Ambiental, v. 27, p. 107-121, 2011. Disponível em: $<$ http://www.remea.furg.br/edicoes/vol27/art8v27.pdf >. Acesso em: 20/01/2012.

KLEIN, A. O turismo rural pedagógico e a função educativa das propriedades rurais: estudo em Porto Alegre, RS, e Joinville, SC. Porto Alegre: FACOS, UFSM Editora, 2013. 216 p. (Dissertações em Turismo Rural, n. 20).

LIBÂNEO, J.C. Pedagogia e pedagogos: para quê? São Paulo: Cortez, 2004.

MARTELLINI, C.; CIABOTTI, F. Progetto sperimentale Agrinido: servizi per la prima infanzia in aree e contesti rurali delle Marche. In: Cittadini in crescita. Centro nazionale di documentazione e analisi per l'infanzia e l'adolescenza, Nuova serie, 2/2014. p. 44-49. Acesso em 05/06/2016. Disponível em: http://www.minori.it/sites/default/files/cittadini in crescita 2 2014.pdf

MORIN, E. Os sete saberes necessários à educação do futuro. São Paulo: Cortez: Brasília, DF: Unesco, 2000.

MORIN, E. A cabeça bem-feita: repensar a reforma, reformar o pensamento. Tradução Eloá Jacobina. 8. ed. Rio de Janeiro: Bertrand Brasil, 2003.

NAPOLI, L. A new reality for italian rural areas: Educational farms. University of Salerno, Italy, 2006. p. 332-345. Disponível em <http://www.openstarts. units.it/dspace/bitstream/10077/865/1/f4napoli.pdf> Acesso em: 16/02/ 2016.

NASOLINI, T. Educare all'ambiente e all'alimentazione. In: BERTOLINI, S. (Ed.). Nuovi educatori ambientali: Esperienze seminariali nel Master in Educazione Ambientale. v. 4, Bologna: Regione Emilia-Romagna, 2005. p. 233- 239. Disponível em: <http://www.ermesambiente.it/wcm/infea/sezioni laterali/formazio ne/master in ea/Master EA/master ea/infean4.pdf>. Acesso em: 20/05/2016.

PENDEZZA, S. Le fattorie didattiche e l'agrinido: l'offerta educativa sostenibile. In: Cittadini in crescita. Centro nazionale di documentazione e analisi per l'infanzia e l'adolescenza, Nuova serie, 2/2014. p. 33-43. Acesso em 05/06/2016. Disponível em: http://www.minori.it/sites/default/files/cittadini in crescita 2 2014.pdf

TEIXEIRA, A. A pedagogia de Dewey. In: DEWEY, J. Vida e educação. 5 ed. São Paulo: Nacional, 1954. p. 3-22.

YUS, R. Educação integral: uma educação holística para o século XXI. Porto Alegre: Artmed. 2002. 